\title{
Prognostic Factors of the Results of Cardiopulmonary Resuscitation in a Cardiology Hospital
}

\author{
Ari Timerman, Naim Sauaia, Leopoldo Soares Piegas, Rui F. Ramos, Carlos Gun, Elizabeth Silva Santos, \\ Antonio C. Mugayar Bianco, J. Eduardo M. R. Sousa \\ São Paulo, SP - Brazil
}

\begin{abstract}
Objective - To analyze the early and late results of cardiopulmonary resuscitation in a cardiology hospital and to try to detect prognostic determinants of both shortand long-term survival.
\end{abstract}

Methods - A series of 557 patients who suffered cardiorespiratory arrest (CRA) at the Dante Pazzanese Cardiology Institute over a period of 5 years was analyzed to examine factors predicting successful resuscitation and long-term survival.

Results - Ressuscitation maneuvers were tried in 536 patients; 281 patients (52.4\%) died immediately, and 164 patients (30.6\%) survived for than 24 hours. The 87 patients who survived for more than 1 month after CRA were compared with nonsurvivors. Coronary disease, cardiomyopathy, and valvular disease had a better prognosis. Primary arrhythmia occurred in $73.5 \%$ of the $>1$ month survivor group and heart failure occurred in $12.6 \%$ of this group. In those patients in whom the initial mechanism of CRA was ventricular fibrillation, $33.3 \%$ survived for more than 1 month, but of those with ventricular asystole only $4.3 \%$ survived. None of the 10 patients with electromechanical dissociation survived. There was worse prognosis in patients included in the extreme age groups (zero to 10 years and 70 years or more). The best results occurred when the cardiac arrest took place in the catheterization laboratories. The worst results occurred in the intensive care unit and the hemodialysis room.

Conclusion - The results in our series may serve as a helpful guide to physicians with the difficult task of deciding when not to resuscitate or when to stop resuscitation efforts.

Key words: cardiorespiratory arrest, acute myocardial infarction

Instituto Dante Pazzanese de Cardiologia

Mailing address: Ari Timerman - Rua Pará, 90/71 - 01243-120 - São Paulo, SP

- Brazil - E-mail: timerman@ originet.com.br
The technique of cardiopulmonary resuscitation (CPR) by external cardiac massage, introduced in 1960 by Kouwenhoven et al ${ }^{1}$, represents a great advance in intensive care medicine and allows many patients to be saved. Several studies on CPR in a hospitalized population have shown the effectiveness of the resuscitation maneuvers with a significant number of patients being discharged alive from general hospitals or from university hospitals, where the studies were carried out. We intend to report here shortand long-term results of our experience with 536 patients who suffered cardiorespiratory arrest (CRA) in a cardiac medical center during a 5-year period and who were followed up for 1 year.

The study was conducted to address questions relating to the demographic and clinical characteristics of patients suffering CRA and also to the predictors of outcome and of long-term survival in an attempt to provide some useful perspectives to physicians involved in CPR.

\section{Methods}

FromFebruary 1, 1978 toFebruary 28, 1983, 339,000outpatient visits and 7694 hospital admissions took place at the Hospital. During this 5-year period, 557 patients suffered cardiac arrest (excluding those that occurred inside the operating room). In 21 terminally ill patients, CPR maneuvers were not initiated. CPR maneuvers were tried in 536 patients.

This institute is specifically dedicated to cardiology, and it has outpatient areas, diagnostic areas and, at the time of this study, 1 hemodialysis room, operating rooms, and a 78-bed hospital. A peculiarity of the hospital was that the operating rooms, the hemodialysis room, the general ward, and the 3 intensive care units (postoperative care unit, intensive care unit, and coronary care unit) were situated on the same floor along a single corridor permitting, therefore, rapid access by physicians, nurses, defibrillators, and drugs to the site of the arrest. The intensive care unit was the place were patients without acute coronary syndromes, but in a critical clinical situation, stayed. 
The institute had a staff that included 120 physicians working in its departments and 60 medical residents. Because of the reduced size of the institute, a specific cardiac arrest team was not available, and therefore, cardiac arrests were attended by the professional house staff, each one having undergone an effective training program in CPR techniques according to the standards of the American Heart Association 2,3.

The CPR training program with the use of mannequins is regularly given, every year, by the doctors responsible from the emergency department to other physicians, nurses, and health professionals working at the institute. The CPR training program is given monthly to medical residents rotating at the emergency department.

CRA, defined as the sudden cessation of circulation, respiration, or both resulting in loss of consciousness and requiring initiation of CPR, was initially attended by the closest physician, nurse, or another health professional while other cardiologists, residents, and nurses from the emergency department proceeded to the site of arrest. After an initial stabilization at the site of the arrest, the patient was transferred to 1 of the intensive care units to continue the treatment.

Every patient who suffered CRA had personal data, the diagnosis, the causes and characteristics of the arrest, and the results of CPR reported on a case report form.

In this study, the time of duration of the CPR maneuvers was not computed. Only the first arrest on each admission was counted. Second or subsequent arrests, if unsuccessfully treated, were recorded as later death and were ignored if the patient survived. One patient was discharged alive from the hospital after successful resuscitation after a first event, and during another hospital admission had another cardiac arrest and died. Only the first cardiac arrest was counted, and the last was recorded as a late death.

At the time of the study and according to the recommendation of the American Heart Association, we considered 3 modalities of cardiac arrest: VF, asystole, and EMD. Respiratory arrest was included as an initial modality of CRA when it resulted in the loss of pulse, which prompted the need for CPR maneuvers. Arrhythmia was classified as primary when it did not occur as a consequence of a significant myocardial contractility depression.

Resuscitation was deemed successful if stable circulation was established and the resuscitators disbanded. The patients who survived the CRA were followed-up through review of their clinical file, personal interviews, letter, phone, or by communications of their personal physician. When necessary, the patient's family was contacted to assess the long-term outcome.

Underlying diseases and determinant causes of CRA were analyzed on the basis of clinical, laboratory, and surgical findings. Postmortem examinations were performed on 97 patients. Particular attention was given to verifying deaths occurring during 48 hours, 30 days, and 1 year after CPR. The variables sex, age, underlying disease, determinant cause, and modality of CRA and the location where the
CRA occurred were considered factors that may have influenced the outcome.

In a preliminary analysis, the association between the mentioned factors and survival was studied. The MantelHaenszel chi-square $\left(\mathrm{x}^{2}\right)$ test without correction for continuity was used in the association tables $(2 \times 2)$. The Pearson $x^{2}$ test was used in the contingency tables to evaluate the homogeneity of survival proportions according the focused factor modalities. If the association was statistically significant, the Cochran procedure was used.

In a second analysis, logistic regression was used to evaluate the value of each factor (age, underlying disease, determinant cause, location, and modality of CRA) without the risk of transitiveness of its influence over the outcome of CPR.

The probability of survival for more than 30 days after CRA and CPR was calculated based on factors that achieved statistical significance in the multivariate analysis, which were the underlying disease, the determinant cause of cardiac arrest, and the modality of CRA. For each of these variables, the condition that indicated a worse prognosis for survival for more than 30 days was selected. For underlying disease, the conditions were cyanotic congenital heart disease, chronic renal failure, and chronic cor pulmonale. For the determinant cause of cardiac arrest, the conditions were heart failure, stroke, and an anoxic spell. For the modality of cardiac arrest, the conditions were asystole and EMD. The three variables were represented by one circle, and these 3 circles were contained in one bigger circle that comprises the entire population studied. The remaining area in the big circle not occupied by the smaller circles comprises the group of patients that do not have any of the conditions of the smaller circles.

Decisions were made using the significance level of 0.05 .

\section{Results}

In the 5-year period comprising the study, CPR was tried in 536 patients; $55(10.3 \%)$ were at the outpatient department and $481(89.7 \%)$ in hospitalized patients (Table I).

The study population consisted of 330 males $(61.6 \%)$ and 206 females (38.4\%) ranging from 9 days to 86 years of age with a mean age of 47.2 years. Table II shows the age distribution of the patients who suffered a CRA.

Table III summarizes the underlying diseases of the patients undergoing resuscitation. The most common underlying disease was coronary heart disease occurring in 163 patients (30.4\%) with 93 patients (57.1\%) in the course of acute myocardial infarction (AMI), followed by cardiomyopathy in 141 patients (26.3\%), and valvular heart disease in 111 patients $(20.7 \%)$.

Of the CRA determinant causes (Table IV), heart failure predominated, occurring in 295 patients (55\%), followed by primary arrhythmia in 88 patients $(16.4 \%)$, respiratory failure in 34 patients $(6.3 \%)$, and stroke in 31 patients $(5.8 \%)$.

It was possible to determine the initial modality of CRA in 492 patients (Table V). Ventricular asystole occurred in 258 patients (48.1\%), VFin 204 patients (38.1\%), isolated 
respiratory arrest in 20 patients (3.7\%), and EMD in $10 \mathrm{pa}-$ tients $(1.9 \%)$.

Analysis of the results of CPR maneuvers revealed that 281 patients (52.4\%) died immediately; another 91 (17\%) died within the first 24 hours after CRA (after an initial recovery). Of the 164 patients (30.6\%) who survived for more than 24 hours, $77(14.4 \%)$ died in the first month after CRA and another 11 (2.1\%) died 1 month to 1 year after CRA (Fig.1). Seventy-six (14.2\%) patients were still alive late 1 year afterCRA.

Data pertaining to the site of arrest and to the outcome of CPR are presented in Table I. The greatest rates of survival were obtained in the cardiac catheterization laboratories (70.3\% of the patient who suffered CRA at that site survived for more than 1 month). The smallest rates of survival occurred in the hemodialysis room, where no patient survived for more than 1 month, and in the emergency room with $8.9 \%$ survival for more than 1 month. The univariate analysis revealed a statistically significant difference when all sites of CRA were compared $\left(x^{2}=92.61, p<0.00001\right)$, when the catheterization laboratory is compared with the hemodialysis room alone $\left(x^{2}=10.66 \mathrm{p}<0.001\right)$ or associated with the

\begin{tabular}{|lccc|}
\hline \multicolumn{4}{|c|}{ Table I - Underlying disease of patients suffering in-hospital } \\
CRA and survival & \\
\hline Underlying disease & $\begin{array}{c}\text { Surv. }> \\
1 \text { month }\end{array}$ & $\begin{array}{c}\text { Non surv. > } \\
1 \text { month }\end{array}$ & Total \\
& $\mathrm{N}(\%)$ & $\mathrm{N}(\%)$ & $\mathrm{N}$ \\
\hline & $36(22,1)$ & $127(77,9)$ & 163 \\
& $24(17,0)$ & $117(83,0)$ & 141 \\
Coronary heart disease & $17(15,3)$ & $94(84,7)$ & 111 \\
Cardiomyopathy & $0(0,0)$ & $45(100,0)$ & 45 \\
Valvular heart disease & $4(17,4)$ & $19(82,6)$ & 23 \\
Cyanotic congenital heart disease & $0(0,0)$ & $13(100,0)$ & 13 \\
Acyanotic congenital heart disease & $0(0,0)$ & $10(100,0)$ & 10 \\
Chronic renal failure & $5(31,3)$ & $11(68,8)$ & 16 \\
Chronic "cor pulmonale" & $0(0,0)$ & $3(100,0)$ & 3 \\
Systemic arterial hypertension & $0(0,0)$ & $3(100,0)$ & 3 \\
Dissecting aneurysm of the aorta & $0(0,0)$ & $3(100,0)$ & 3 \\
Primary pulmonary hypertension & $1(20,0)$ & $4(80,0)$ & 5 \\
Carcinoma & $87(16,2)$ & $449(83,8)$ & 536 \\
Others & & \\
Total &
\end{tabular}

\begin{tabular}{|lccc|}
\hline \multicolumn{4}{|c|}{ Table II - Determinant causes of patients suffering in- hospital } \\
CRA and survival \\
\hline Determinant Cause & Surv. $>1$ month & Non surv. $>1$ month & Total \\
& $(\%)$ & $(\%)$ & N \\
\hline Heart failure & $11(3,7)$ & $284(96,3)$ & 295 \\
Primary arrythmia & $64(72,7)$ & $24(27,3)$ & 88 \\
Respiratory failure & $4(11,8)$ & $30(88,2)$ & 34 \\
Stroke & $0(0,0)$ & $31(100,0)$ & 31 \\
Anoxic spell & $0(0,0)$ & $19(100,0)$ & 19 \\
Uremia & $1(5,9)$ & $16(94,1)$ & 17 \\
Infectious diseases & $0(0,0)$ & $16(100,0)$ & 16 \\
Hypovolemic shock & $1(8,3)$ & $11(91,7)$ & 12 \\
Cardiac tamponade & $0(0,0)$ & $3(100,0)$ & 3 \\
Hiperkalemia & $1(33,3)$ & $2(66,7)$ & 3 \\
Hipokalemia & $4(66,7)$ & $2(33,3)$ & 6 \\
Mesenteric thrombosis & $0(0,0)$ & $2(100,0)$ & 2 \\
Others & $1(10,0)$ & $9(90,0)$ & 10 \\
Total & $87(16,2)$ & $449(83,8)$ & 536 \\
\hline
\end{tabular}

\begin{tabular}{|lccc|}
\hline \multicolumn{4}{|c|}{ Table III -Modalities of CRA in patients suffering in- hospital } \\
CRA and survival \\
\hline Modality & $\begin{array}{c}\text { Surv. }> \\
\text { 1 month N(\%) }\end{array}$ & $\begin{array}{c}\text { Non surv. }> \\
1 \text { month N(\%) }\end{array}$ & $\begin{array}{c}\text { Total } \\
\mathrm{N}\end{array}$ \\
\hline Ventricular asystole & $11(4,3)$ & $247(95,7)$ & 258 \\
EMD & $0(0,0)$ & $10(100,0)$ & 10 \\
Ventricular fibrilation & $68(33,3)$ & $136(66,7)$ & 204 \\
Respiratóry arrrest & $5(25,0)$ & $15(75,0)$ & 20 \\
Unknown & $3(6,8)$ & $41(93,2)$ & 44 \\
Total & $87(16,2)$ & $449(83,8)$ & 536 \\
\hline
\end{tabular}

emergency room $\left(x^{2}=85.15\right.$ and $\left.p<0.00001\right)$. In the multivariate analysis, no significant statistical difference at 1 month $(\mathrm{p}<0.4)$ occurred.

CPR was initiated within 5 minutes of the arrest in $97.8 \%$ of the cases, and all patients who survived for more than 1 month were in this situation.

In the group of 87 patients who survived for more than 1 month after recovery from CRA, the age ranged from 11 to 83 years, with a mean age of 49 years. In the group of 449 patients who died within 1 month, the age ranged from 9 days to 86 years, with the mean age being 46.9 years. When the patients are divided into 3 age groups (zero to 10 years, 11 to 69 years, and 70 years or more), we observed that no patient survived for more than 1 month of the 45 patients aged between zero and 10 years. Of the 70 patients 70 years or older, the survival rate for more than 1 month was only $5.7 \%$. Of the 421 patients aged between 11 and 69 years, $19.7 \%$ survived for more than 1 month. This difference was statistically significant with $x^{2}=18.17$ and $p<0.0001$ (Table VI). When we compared the age groups of zero to 10 years and 70 years or more with the age group of patients 11 to 69 years, we confirmed the significant statistical difference with $\mathrm{x}^{2}=17.51$ and $p<0.00002$. In the multivariate analysis, however, when compared with other factors, statistical significance at 30 days ( $\mathrm{p}<0.25)$ was not sustained. In the group of 87 patients surviving for more than 1 month, 51 patients $(58.6 \%)$ were male and $36(41.4 \%)$ were female. In the nonsurviving group, 279 were male $(62.1 \%)$ and $170(37.9 \%)$ were female. No significant statistical difference existed between the number of survivors according to sex (Mantel-Haenszel $x^{2}=0.38$ and $\mathrm{p}<0.53$ ).

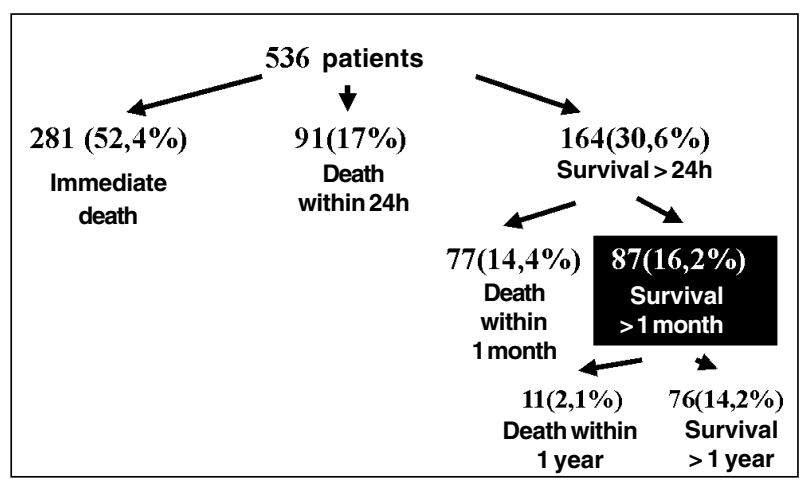

Fig. 1 - Results of in-hospital CPR. 
In the group of patients surviving for more than 1 month, the most common underlying disease was coronary heart disease, occurring in 36 patients $(41.4 \%)$ with $21 \mathrm{pa}-$ tients (58.3\%) dying during the course of AMI. Cardiomyopathy was present in 24 patients (27.6\%), valvular heart disease in 17 patients $(19.5 \%)$, isolated high blood pressure in 5 patients $(5.7 \%)$, acyanotic congenital heart disease in 4 patients $(4.6 \%)$ and sinus node disease in 1 patient $(1.1 \%)$ (Table III). In the non-survivor group, coronary heart disease predominated, occurring in 127 patients (28.3\%) with 72 patients $(56.7 \%)$ dying during the course of AMI. Cardiomyopathy occurred in 117 patients $(26.1 \%)$, valvular heart disease in 94 patients (20.9\%), and cyanotic congenital heart disease in 45 patients (10\%). Limiting the comparison to the most common diseases (coronary heart disease, cardiomyopathy, and valvular heart disease), no significant statistical difference existed among those who survived for more than 1 month after the event $\left(x^{2}=2.3\right.$ and $\left.p<0.31\right)$. When we compare the group of these 3 diseases with the group comprising cyanotic congenital heart disease, chronic renal failure, and chronic cor pulmonale, the difference among the proportions of those who survived for more than 30 days was statistically significant $\left(x^{2}=15.0\right.$ and $\left.p<0.0001\right)$. In the multivariate analysis, the statistical significance persisted $(\mathrm{p}<0.002)$.

As to CRA determinant causes, in the group surviving for more than 1 month, primary arrhythmia predominated, occurring in 64 patients $(73.6 \%)$, followed by heart failure in 11 patients $(12.6 \%)$, respiratory failure in 4 patients (4.6\%), hypokalemia in 4 patients (4.6\%). In the group of 449 patients who died within 1 month after CRA, heart failure predominated, occurring in 284 patients $(63.3 \%)$ followed by stroke in 31 patients $(6.9 \%$ ), respiratory failure in $30 \mathrm{pa}-$ tients $(6.7 \%)$, and primary arrhythmia in 24 patients $(5.3 \%)$ (Table IV). Comparing the proportions of those who survived for more than 1 month documented with heart failure and primary arrhythmia, the difference was statistically significant $\left(x^{2}=204.9\right.$ and $\left.p<0.00001\right)$. The difference was also significant when primary arrhythmia was compared with heart failure, stroke, and anoxic spells $\left(\mathrm{x}^{2}=236.8\right.$ and $\mathrm{p}<0.00001)$. In the multivariate analysis, the statistical significance persisted $(\mathrm{p}<0.02)$.

VF was the most common initial CRA modality in the survivor group, occurring in 68 patients $(78.2 \%)$, followed by ventricular asystole occurring in 11 patients $(12.6 \%)$, and respiratory arrest in 5 patients (5.7\%). In 3 patients (3.4\%), we could not identify the initial CRA modality. In the non-survivor group, asystole predominated, occurring in 247 patients (55\%) followed by VF in 136 patients (30.3\%), respiratory arrest in 15 patients (3.3\%), and EMD in $10 \mathrm{pa}-$ tients $(2.2 \%)$. The initial CRA modality could not be identified in 41 patients $(9.1 \%)$ in this group (Table V). A statistically significant association existed between survival for more than 30 days and the initial CRA modality $\left(x^{2}=70.94\right.$ and $\mathrm{p}<0.00001$ ). Comparing the groups by using the Cochran method, we verified that no difference existed between groups with asystole and those with EMD $\left(x^{2}=0.44\right)$ or between groups with $\mathrm{VF}$ and with respiratory arrest $\left(\mathrm{x}^{2}=\right.$
0.57). Comparing the patients who had asystole or EMD with those who had VF or respiratory arrest, we found a significant statistical difference $\left(x^{2}=69.9\right.$ and $\left.p=0.00001\right)$. The difference was also statistically significant when we compared VF with asystole, both isolated $\left(\mathrm{x}^{2}=67.91\right.$ and $\mathrm{p}<0.00$ $001)$ or associated with EMD $\left(x^{2}=71.01\right.$ and $\left.p<0.00001\right)$. In the multivariate analysis, the statistical significance $(\mathrm{p}<0.0001)$ persisted.

Those patients discharged alive from the hospital were followed-up for 1 year; after that period 76 patients were alive (14.2\%).

To calculate the probability of survival after CRA and CPR, we utilized the factors that reached statistical significance in the logistic regression: underlying disease, determinant cause, and initial modality of CRA. Each factor constituted a group with the characteristics with of an inverse relation to survival for more than 30 days after the event (Fig. 2, Table VII). A significant statistical difference existed among the proportions of those who survived for more than 30 days according the subgroups and their complements $\left(x^{2}=256.38\right.$ and $\left.p<0.00001\right)$.

In the subgroup of patients without any characteristics of the three big groups, the survival for more than 30 days was $69 \%$. In the subgroup with at least 1 characteristic of each big group, the survival for more than 30 days was zero. Comparing these 2 subgroups, we observed a significant statistical difference $\left(x^{2}=37.34\right.$ and $\left.p<0.00001\right)$.

\section{Discussion}

The success rate of CPR from out-of-hospital CRA is significantly associated with short time intervals from collapse to initiation of basic life support (BLS) (within 4 minutes) and to provision of advanced cardiac life support (ACLS), mainly cardiac defibrillation (within 8 minutes) ${ }^{4-11}$, obtaining a mean of $19 \%$ of these patients discharged alive from the hospital ${ }^{12-15}$.

When CRA occurs inside the hospital, it becomes easier to apply BLS and ACLS ${ }^{16-18}$.

In the specific case of DPCI, which is specifically dedicated to cardiology with the peculiarity of having, at the time of this study, most of its installations localized on the same floor along a single corridor, these facilities are accentuated permitting, therefore, rapid arrival of physicians, nurses, defibrillators, and drugs to the site of the arrest. This group of patients has been previously reported in the literature ${ }^{19}$.

Time to initiation of CPR in the vast majority of the cases $(97.8 \%)$ was less than 5 minutes, and all patients who survived for more than 1 month were in this situation. For this reason, it becomes evident that other important factors may have an influence on the results of CPR inside a hospital. Bedell et al ${ }^{20}$, DeEbard ${ }^{21}$, Rozenbaum and Shenkman ${ }^{22}$ and Suljaga-Pechtel et al ${ }^{23}$ suggest that the location where an arrest occurs is not an important determinant of survival after CRA, when patients receive prompt resuscitation. However, we obtained better results in the cardiac catheteri- 


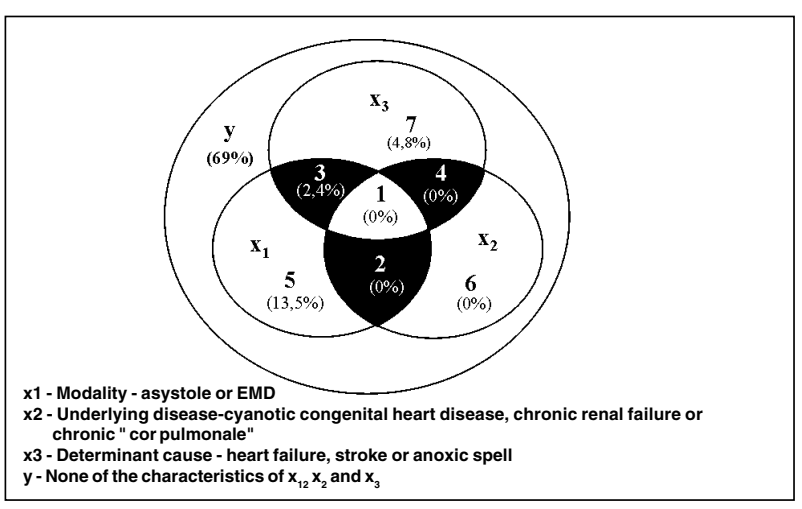

Fig. 2 - CPR prognostic evaluation.

\begin{tabular}{|cccc|}
\hline \multicolumn{5}{|c|}{ Table IV - Case distributions of CPR according to patients and } \\
CRA characteristics
\end{tabular}

zation laboratories, with $70.3 \%$ of patients surviving over 1 month after cardiac arrest. Similar results are cited by Gilston ${ }^{24}$, Jeresaty et $\mathrm{al}^{25}$, McGrath ${ }^{26}$ and Tortolani et al ${ }^{27}$ probably because the major determinant cause of cardiac arrest in these laboratories is primary arrhythmia. Other authors ${ }^{28-32}$ observed that CRA occurring in certain locations, such as the coronary unit, also has a better prognosis.

The worst results in our study occurred in the hemodialysis room and intensive care unit with $0 \%$ and $8.9 \%$ survival for more than 1 month, respectively. This may well be due to the fact that these patients belonged to a highrisk group, with a more severe underlying disease. Univariate analysis revealed a significant statistical difference when the different locations of the CRA were compared $(\mathrm{p}<0.00$ 001 ) and when the catheterization laboratory was compared with the hemodialysis room alone $(\mathrm{p}<0.001)$ or in association with the intensive care unit $(\mathrm{p}<0.00001)$. In the multivariate analysis, however, no significant statistical difference $(\mathrm{p}<0.4)$ occurred showing that underlying disease, CRA determinant cause, and CRA modality are the most important factors and that the location simply houses patients with similar characteristics.

Coronary heart disease, cardiomyopathy, and valvular heart disease were the most frequent underlying diseases, in the general group, in the group of 87 patients who survived for more than 1 month, and in the group of those who did not survive for more than 1 month. Patients with these 3 diseases had a better prognosis when compared with others, regarding survival for more than 1 month. No survivors of CRA existed in the 45 patients with cyanotic congenital heart disease, in the 15 patients with chronic renal failure, or in the 8 patients with chronic cor pulmonale. This difference reached statistical difference both in the univariate $(\mathrm{p}<0.0001)$ and in the multivariate analysis $(\mathrm{p}<0.002)$. These findings are in accordance with the observations of other authors ${ }^{24,33-36}$.

No significant statistical difference existed regarding sex distribution between the survivors and nonsurvivors beyond 1-month; this fact is also reported in the literature ${ }^{22,24,27,37-41}$.

Our series demonstrated a poorer prognosis for patients included in the extreme age groups, which is in accordance with some authors $20,23,26,28,30,32,33,37,42-51$, but in disagreement with others ${ }^{21,22,24,25,36,41,52-62}$. No patients survived for more than 1 month among the 45 patients aged between 0 and 10 years. Of the 70 patients $>70$ years who underwent resuscitation, only 4 survived for more than 1 month (5.7\%). The best results occurred in groups whose age varied from 26 to 30 years $(33.3 \%)$ and from 46 to 50 years $(25 \%)$. We compared the groups of patients with age varying between 0 and 10 years and patients $>70$ years with the group of patients whose age ranged from 11 to 69 years, obtaining a significant statistical difference $(\mathrm{p}<0.00002)$. In the multivariate analysis, age looses its statistical significance $(\mathrm{p}<0.25)$. The mean age of the survival group was higher than that of the nonsurvival beyond 1-month group, perhaps because of the high mortality rate of the younger group. These data, however, must be analyzed with caution. The greatest part of the younger group (age between 0 and 10 years) was formed by patients with cyanotic congenital heart disease, and this fact (and not the age itself) may have determined the poorer outcome in this age group. CRA that occurs in children without serious organic disease, in a high percentage of the cases is due to upper airway obstruction, and when patients receive prompt treatment they have a good prognosis ${ }^{63-68}$. Horimoto et al ${ }^{69}$ had an initial CPR success rate of $30 \%$ and hospital discharge of $21 \%$ in a group of 43 pediatric patients who suffered a CRA caused mainly by airway obstruction.

Regarding CRA determinant cause in the general group, a net predominance existed of heart failure, which is was present in 295 of 536 patients of the entire group, corresponding to $55 \%$, and primary arrhythmia was the determinant cause in $88(16.4 \%)$ patients. However, in the group of 87 patients who survived for more than 1 month, an inversion occurred in this order, with primary arrhythmia being the determinant cause in $64(73.6 \%)$ patients and heart failure being the cause in $11(12.6 \%)$ patients. In the group of 449 patients who did not survive for more than 1 month, heart failure was the determinant cause of CRA in $284(63.3 \%)$ patients and primary arrhythmia in $24(5.3 \%)$ patients. This difference is statistically significant $(\mathrm{p}<0.00$ $001)$. These findings were observed by other authors ${ }^{20,70}$.

Thus, of 295 patients with heart failure, only $11(3.7 \%)$ 
survived for more than 1 month; of 88 patients with primary arrhythmia 64(72.7\%) survived for more than 1 month. In the multivariate analysis, the CRA determinant cause was a statistically significant factor with $\mathrm{p}<0.02$.

Cardiac arrest in VF had quite a better prognosis than that in ventricular asystole or in EMD: our findings are consistent with the observations of other authors $18,23,26,32,33,36,54,57,60,71-77$.

Of 204 patients with cardiac arrest in VF, $68(33,3 \%)$ survived for more than 1 month, but only 11 of $258(4.3 \%)$ patients who suffered cardiac arrest in ventricular asystole survived for more than 1 month. None of the 10 patients with cardiac arrest in EMD survived $(\mathrm{p}<0.00001)$. The statistical difference was also observed in the multivariate analysis with $\mathrm{p}<0.0001$.

Our study revealed an immediate success rate of $47.6 \%$ with CPR maneuvers; this rate dropped to $30.6 \%$ at the first 24 hours. Eighty-seven patients $(16.2 \%)$ survived for more than 1 month, and 76 (14.2\%) patients were alive after 1 year (Fig. 1). These findings are comparable to those of previous studies ${ }^{16,20,23,28,71,78-82}$ (Table VIII).

Our findings, therefore, showed a higher CPR success and survival rate for more than 1 month in those patients included in 1 of the following categories: age between 11 and 69 years, with CRA occurring in the cardiac catheterization laboratories, with coronary heart disease, cardiomyopathy, or valvular heart disease being the underlying disease; primary arrhythmia being the determinant cause; and VF or respiratory arrest being the initial modality of CRA.

The worst results occurred in those patients included in 1 of these categories: age between 0 and 10 years or $>70$ years, CRA occurring in the hemodialysis room or intensive care unit with underlying disease being cyanotic congenital heart disease, chronic renal failure, or chronic cor pulmonale, with the determinant cause being heart failure, stroke, or an anoxic spell, and ventricular asystole or EMD being the initial modality of CRA.

In the multivariate analysis, only underlying disease, CRA determinant cause, and the initial modality obtained statistical significance. Age and location of CRA lost statistical significance in the multivariate analysis, because some underlying diseases, determinant causes, and initial modality of CRA are more frequent in certain age groups and when they occur in specific places of CRA (Table IX).

These results may serve as a helpful guide to physicians in the hard task of deciding when not to resuscitate or when to stop with resuscitation efforts.

Attempts to determine parameters that estimate the possibility of success of in-hospital resuscitation maneuvers induced some authors to propose prognostic indexes.

The APACHE index (Acute Physiology and Chronic Health Evaluation) created by Knaus et $\mathrm{al}^{34,35}$ is a system to classify the severity of diseases. Peterson et al ${ }^{83}$ applied the APACHE II index retrospectively in 114 patients who suffered CRA and verified that those who were discharged alive from the hospital had an APACHE index smaller than the nonsurvivors.

Kentsch et al ${ }^{84}$ in Hamburg, proposed a prognostic score of out-of-hospital CRA based on parameters as age, CRA modality, type of respiratory arrest, pupil state, and aspiration. Martens et al $^{48}$ applied this score retrospectively in 6178 patients with in- and out-of-hospital CRA; the Kentsch score could not show an appropriate correlation with the results of CPR.

The KPS score (Karnofsky Performance Status) ${ }^{85}$ was initially utilized to categorize the physical ability of patients with cancer on a scale from 1 (almost dying) to 10 (totally normal). Brezinski et al ${ }^{86}$ applied this score in 849 patient with AMI. Those with KPS scores less than 8 had more heart failure, in-hospital CRA, and death compared with those with a score of 8 or greater.

George et $\mathrm{al}^{45}$ proposed the PAM index (Pre Arrest Morbidity) to evaluate the prognosis of patients who suffered a CRA and in whom CPR was tried inside a hospital. This index was based on the study of Bedell et al ${ }^{20}$, attributing the higher scores to those factors significantly associated with in-hospital mortality in the multivariate analysis (pneumonia, hypotension, renal failure, cancer, and a sedentary lifestyle before hospitalization). A lower score was attributed to other variables.

His index was applied in 140 hospitalized patients who suffered CRA and in whom CPR was tried; $55 \%$ had an immediate success on resuscitation and $24.3 \%$ were discharged alive from the hospital. The PAM index had a negative and statistically significant association with survival to hospital discharge. Survival to hospital discharge of patients with a PAM index of zero was $50.6 \%$, and no patient with a PAM score higher than 8 survived long enough for hospital discharge. The PAM index, therefore, may be helpful in identifying patients in whom CPR may be ineffective.

Ebell ${ }^{37}$ proposed a modification in the PAM index based on a metaanalysis of 14 studies of survival after in-hospital CPR including 2643 patients, reducing the variables from 15 to 8 , metastatic cancer being that with the worst prognosis. Interestingly, AMI was associated with a high percentage of survival for hospital discharge, receiving a negative score. O' Keefe and Ebell ${ }^{70}$ named this modified PAM index the PAR (Prognostics After Resuscitation) score and compared the PAM index with the PAR score as a prognosis of nonsuccess on survival after in-hospital CPR in a population of 274 patients described by O'Keefe ${ }^{49}$. The PAR score was considered better than the PAM index as predictor of unsuccessful CPR.

The difference in the results of CPR could be due to different periods (the improvement in CPR techniques should help to obtain better results), to the characteristics of the study population, and to the selection of patients who suffered a CRA and underwent resuscitation maneuvers.

In countries where specific legislation exists permitting prior discussion among physicians, patients, and their family about the use of resuscitation maneuvers the possibility of do not to resuscitate ("DNR"orders) exists, providing physicians protection for their beliefs and respecting the wishes of patients and their families ${ }^{17,45,87-93}$.

Tucker et al ${ }^{40}$ proposed the "Resuscitation Fraction" 


\begin{tabular}{|c|c|c|c|c|c|}
\hline \multicolumn{6}{|c|}{ Table V - World experience of in-hospital CRA } \\
\hline Reference & Year & No. patients & Immediated Survival (\%) & Late \% Hospitalar & discharge survival \\
\hline & Stemmler ${ }^{61}$ & 1965 & 103 & $\begin{array}{c}+1 \mathrm{~h}(35) \\
+24 \mathrm{~h}(12,6)\end{array}$ & $4,8 \mathrm{NR}$ \\
\hline Gilston $^{24}$ & 1965 & 37 & $(55)$ & 35 & NR \\
\hline Johnson et al. ${ }^{79}$ & 1967 & 552 & $+24 \mathrm{~h}(31,7)$ & 14,9 & NR \\
\hline Hollingsworth $^{54}$ & 1969 & 368 & $+24 \mathrm{~h}(24,7)$ & 8,2 & NR \\
\hline Jeresaty et al. ${ }^{79}$ & 1969 & 237 & (41) & 22 & $9-42$ m.- $18,1 \%$ \\
\hline Camarata et al. ${ }^{79}$ & 1971 & 132 & (38) & 5 & NR \\
\hline Castagna et al..$^{79}$ & 1974 & 137 & (35) & 10 & NR \\
\hline Peatfield et al. ${ }^{79}$ & 1977 & 1063 & $(32,5)$ & 8,7 & $10 \mathrm{y}-3,7 \%$ \\
\hline Bedell et al. ${ }^{79}$ & 1983 & 294 & $\begin{array}{l}+1 \mathrm{~h}(44) \\
+24 \mathrm{~h}(33)\end{array}$ & 14 & $6 \mathrm{~m}-11,2 \%$ \\
\hline Suljaga-Pechtel et al. ${ }^{79}$ & 1984 & 207 & $(40,5)$ & 14 & $6 m-10,3 \%$ \\
\hline Horimoto et al. ${ }^{79}$ & 1985 & 43 & (30) & 21 & NR \\
\hline Ballin ${ }^{42}$ & 1986 & 200 & (18) & 7 & NR \\
\hline Kyff et al. ${ }^{79}$ & 1987 & 272 & $(37,5)$ & 11 & NR \\
\hline Goldberg et al. ${ }^{79}$ & 1987 & 667 & $\mathrm{NR}$ & 22 & $9 y-13,6 \%$ \\
\hline Rozenbaum et al. ${ }^{79}$ & 1988 & 71 & (41) & 18 & NR \\
\hline Timerman et al. ${ }^{79}$ & 1989 & 536 & $+24 \mathrm{~h}(28)$ & $\mathrm{NR}^{*}$ & $9 y-8,0 \%$ \\
\hline George et al. ${ }^{79}$ & 1989 & 140 & $(55)$ & 24,3 & $3 m-20,7 \%$ \\
\hline Roberts et al. ${ }^{79}$ & 1990 & 310 & $(37,1)$ & 9,7 & NR \\
\hline Hendrick et al. ${ }^{79}$ & 1990 & 90 & $(49,5)$ & 16,5 & $7,1 \mathrm{~m}-14,3 \%$ \\
\hline Tortolani et al. ${ }^{79}$ & 1990 & 470 & $+24 \mathrm{~h}(33)$ & 15 & NR \\
\hline O'Keeffe et al. ${ }^{79}$ & 1991 & 274 & $(29,9)$ & 9,1 & NR \\
\hline & Tunstall-Pedoe et al. ${ }^{79}$ & 1992 & 2.838 & $+1 \mathrm{~h}(45)$ & \\
\hline$+24 \mathrm{~h}(32)$ & 21 & $15 \%$ & & & \\
\hline & Doig C. J. et al. ${ }^{79}$ & 2000 & 239 & NR & $21,3 \mathrm{NR}$ \\
\hline
\end{tabular}

\begin{tabular}{|lccc|}
\hline \multicolumn{4}{|c|}{ Table VI - Multivariate analysis } \\
\hline \multicolumn{4}{|c}{ P } \\
Factor & 48 hours & 30 days & 1 year \\
\hline Location of CRA & $<0,03$ & $<0,4$ & $<0,3$ \\
Age group & $<0,19$ & $<0,25$ & $<0,57$ \\
Underliyng diesease & $<0,01$ & $<0,002$ & $<0,005$ \\
Determinante cause of CRA & $<0,03$ & $<0,02$ & $<0,01$ \\
Modality of CRA & $<0,0001$ & $<0,0001$ & $<0,0001$ \\
\hline
\end{tabular}

(RF) that shows the group of persons in whom CPR was tried compared with the entire population that suffered CRA. They utilized the following formula:

$\frac{\text { CPR tried }}{\text { Total of CRA }} \times 100=$ RF

In their study of a total of 270 patients who suffered CRA in one year, CPR was tried in 80 (in 190 a previous "DNR" order existed). RF was, therefore, $29.6 \%$. In the study of George et al ${ }^{45}, \mathrm{RF}$ was $43 \%$, which is similar to that of Lemire and Johnson ${ }^{56}$.

Our study was carried out in a cardiology hospital, with a smaller incidence of cancer, which is the most frequent disease in patients with DNR orders in general hospitals ${ }^{45,56}$. Consequently, the greater incidence of severe cardiac diseases makes it difficult in many situations not to try CPR, for example in patients like with congenital cyanotic heart disease. This fact is accentuated by the lack of specific legislation in our country that may protect physicians and patients in their decision to withhold resuscitation, and the lack of a wide public debate about this issue. RF in our se- ries was $96 \%$. This number demonstrates by itself that probably a significant percentage of patients may undergo CPR without hope of success.

The practical applicability of these prognostic CPR indexes is arguable, not only for their complexity in the urgent situation imposed by CRA and CPR but also by the fact that these indexes are based on different studies, with different $\mathrm{RF}$ in populations with unequal characteristics, coming sometimes to conflicting conclusions.

The knowledge of certain characteristics of the patient who suffers CRA may help us with the judgment of the validity of the implementation or the abandonment of resuscitation efforts, without the need for using prognostic indexes.

Some factors have been showing an important correlation with the failure of CPR maneuvers in different studies: duration of CPR longer than 15 minutes ${ }^{20,22,27,71,73,94}$, stroke 20,70 $^{20}$, cardiac arrest in a different rhythm than $\mathrm{VF}^{9,26,27,57,60,71,73-75,77,94,95}$, chronic renal failure ${ }^{20,24,36,96}$, chronic cor ulmonale ${ }^{34,35}$, cyanotic congenital heart disease ${ }^{19}$, metastatic cancer ${ }^{20,37,49,55,83,96}$, sepsis $^{20,22,37,83,96}$, unwitnessed CRA ${ }^{25,48,51}$, and time to initiate CPR longer than 5 minutes $6,7,10,13,33,96$.

Tortolani et al ${ }^{27}$ analyzing 512 in-hospital CPRs verified that when the patient was older than 68 years, CRA occurring in the emergency unit, in asystole, when a defibrillator was used, tracheal intubation, intravenous administration of more than 1 drug or dropping more than 1 inotropic or vasopressor, the in-hospital mortality was $100 \%$. When the patient did not have any of those characteristics, mortality was $35.7 \%$.

In our series, when a patient suffered a CRA in asysto- 
le or EMD, had congenital cyanotic heart disease, chronic renal failure, or chronic cor pulmonale, having as the CRA determinant cause heart failure, stroke, or an anoxic spell, none survived for more than 1 month. In those without any of these characteristics, survival for more than 1 month was $69 \%$ ( $p<0.00001$ ) (Fig. 2 and Table VI). When we compare the 3 groups of adverse CPR outcome factors and underlying disease ( $\mathrm{x}_{2}$ group on Fig 2 and Table VI), lack of survival for more than 30 days acquires prognostic value greater than the CRA determinant cause ( $x_{3}$ group) and than the initial CRA modality ( $\mathrm{x}_{1}$ group).
The results of our study may help to identify prognostic factors of in-hospital CPR and may be used to support, on a rational basis, the implementation of specific legislation in our country about the decision of not to resuscitate or to abandon the resuscitation efforts.

The data here presented may provide useful information to physicians in the hard task of deciding when not to resuscitate or when to stop with resuscitation efforts. The thorough consideration of this information may help to dispel the anxiety of patients and their family and to reduce the costs that may result from the use of heroic measures destined to fail.

\section{References}

1. Kouwenhoven WB, Jude JR, Knikerbocker GG. Closed-chest cardiac massage. JAMA 1960; 173: 1064-7.

2. Standards and guidelines for cardiopulmonary resuscitation (CPR) and emergency cardiac care (ECC). JAMA 1980; 244: 453-509.

3. Standards for cardiopulmonary resuscitation (CPR) and emergency cardiac care (ECC). JAMA 1974; 227: 833-68.

4. Atkins JM. Emergency medical service systems in acute cardiac care: state of the art. Circulation 1986; 74(Suppl. 4 - Part 2): 4-8.

5. Cummins RO, Eisenberg MS. Prehospital cardiopulmonary resuscitation: is it effective? JAMA 1985; 253: 2408-12.

6. Cummins RO, Ornato JP, Thies WH, Pepe PE. Improving survival from suddencardiac arrest: the "chain of survival"concept: a statement for health professionals from the advanced cardiac life support subcommittee and the Emergency Cardiac Care Committee of American Heart Association. Circulation 1991; 83: 1832-47

7. Eisenberg MS, Bergner L, Hallstrom AP. cardiac resuscitation in the community: importance of rapid provision and implications for program planning. JAMA 1979; 241: 1905-7.

8. Hallstrom AP, Cobb LA, Swain M, Mensinger K. Predictors of hospital mortality after out-of-hospital cardiopulmonary resuscitation. Crit Care Med 1985; 13: 927-9.

9. Kaye W, Mancini ME, Rallis SF, et. Can better basic and advanced cardiac life support improve outcome from cardiac arrest? Crit Care Med. 1985; 13:916-20.

10. Stiell IG, Wells GA, De Maio VJ, et al. Modifiable Factors Associated with Improved Cardiac Arrest Survival in a Multicenter Basic Life Support Defibrillation System: OPALS Study Phase I. Results. Ann Emerg Med 1999; 33: 44-50.

11. Becker LB, Han BH, Meyer PM, et al. Racial differences in the incidence of cardiac arrest and subsequent survival. N Engl J Med 1993: 329: 600-6.

12. Cummins RO, Eisenberg MS, Litwin PE, Hallstrom AP. Survival benefit of prehospital cardiopulmonary resuscitation for cardiac arrest. Crit Care Med 1985; 13: 944-5.

13. Eisenberg MS, Hallstrom AP, Bergner L. Long-term survival after-out-hospital cardiac arrest. N Engl J Med 1982; 306: 1340-3.

14. Myerburg RJ, Conde CA, Sung RJ, et al. Clinical, electrophysiologic and hemodynamic profile of patients resuscitated from pre-hospital cardiac arrest. Am J Med 1980; 68: 568-76.

15. Tresh DD, Keelan Jr. MH. Long-term survival after pre-hospital sudden cardiac death. Am Heart J 1984; 108: 1-5.

16. Becker LB. The epidemiology of sudden death. In: Paradis NA, Halperin HR, Nowak RM. Cardiac Arrest: The Science and Practice of Resuscitation Medicine. Baltimore: Williams \& Wilkins, 1996: 28-48.

17. Cummins RO, Chamberlain D. Consensus development in resuscitation: the growing movement toward international emergency cardiac care guidelines. In: Paradis NA, Halperin HR, Nowak RM. Cardiac Arrest: the Science and Practice of Resuscitation Medicine. Baltimore: Williams \& Wilkins, 1996: 935-51.

18. Kern KB, Ewy GA. Cardiopulmonary resuscitation in patients with acute myocardial infarction. In: Francis GS, Alpert JS. Coronary Care. $2^{\text {nd }}$ Ed. Boston: Little Brown, 1995: 367-86.

19. Timerman A, Piegas LS, Sousa JEMR. Results of cardiopulmonary resuscitation in a cardiology hospital. Resuscitation 1989; 18: 75-84.

20. Bedell SE, Delbanco TL, Cook EF, Epstein FH. Survival after cardiopulmonary resuscitation in the hospital. N Engl J Med 1983; 309: 569-76.

21. DeEbard ML. Cardiopulmonary resuscitation: analysis of six years'experience and review of the literature. Ann Emerg Med 1981; 10: 408-16.
22. Rozenbaum EA, Shenkman L. Predicting outcome of in-hospital cardiopulmonary resuscitation. Crit Care Med 1988; 16: 583-6.

23. Suljaga-Pechtel K, Goldberg E, Strickon P, Berger M, Skovron ML. Cardiopulmonary resuscitation in a hospitalized population: prospective study of factors associated with outcome. Resuscitation 1984; 12: 77-95.

24. Gilston A, Leeds MB. Clinical and biochemical aspects of cardiac resuscitation Lancet 1965; 2: 1039-43.

25. Jeresaty RM, Godar TJ, Liss JP. External cardiac resuscitation in a community hospital: a three year experience. Arch Intern Med 1969; 124: 588-92.

26. McGrath RB. In-house cardiopulmonary resuscitation: after a quarter of a century. Ann Emerg Med 1987; 16: 1365-8.

27. Tortolani AJ, Risucci DA, Rosati RJ, Dixon R. In-hospital cardiopulmonary resuscitation: patient, arrest and resuscitation factors associated with survival. Resuscitation 1990; 20: 115-28.

28. Tunstall-Pedoe M, Bailey L, Chanberlain DA, Marsden AK, Ward ME, Zideman DA. Survey of 3.765 cardiopulmonary resuscitations in British hospitals (the BRESUS study): methods and overall results. Br Med J ANO???; 304: 1347-51.

29. Burns R, Graney MJ, Nichols LO. Prediction of in-hospital cardiopulmonary arrest outcome. Arch Intern Med 1989; 149: 1318-21.

30. Frabicius-Bierre N, Astvad K, Kiaerulff J. Cardiac arrest following acute myocardial infarction: a study of 285 cases from three medical departments using a joint acute admission section containing a coronary care unit. Acta Med Scand 1974; 195: 261-5.

31. Stiles AR, Tucker BL, Meyer BW, Lindesmith GG, Jones JC. Cardiopulmonary arrest evaluation of an active resuscitation program. Am J Surg 1971; 122 : 282-7.

32. Wildsmith JAW, Dennyson, W.G.; MYERS, K.W. Results of resuscitation following cardiac arrest: a review from a major teaching hospital. Br J Anaesth 1972; 44: 716-20.

33. Herlitz J, Ekström L, Wennerblom B, Axelsson A, Bang A, Holmberg S. Risk indicators for, and symptoms associated with death among patients hospitalized after out-of-hospital cardiac arrest: pathophysiology and natural history. Coron Artery Dis 1994; 5: 407-14

34. Knaus WA, Draper EA, Wagner DP, Zimmerman JE. Apache II; a severity of disease classification system. Crit Care Med 1985; 13: 818-29.

35. Knaus WA, Wagner DP, Draper EA, et al. The Apache III: prognostic system risk prediction of hospital mortality for critically ill hospitalized adults. Chest 1991; 100: 1619-36.

36. Roberts D, Landolfo K, Light RB, Dobson K. Early predictors of mortality for hospitalized patients suffering cardiopulmonary arrest. Chest 1990; 97: 413-9.

37. Ebell MH. Prearrest predictors of survival following in-hospital cardiopulmonary resuscitation: a meta-analysis. J Fam Pract 1992; 34: 551-8.

38. Sack JB, Kesselbrenner MB, Bregman D. Survival from in-hospital cardiac arrest with interposed abdominal counterpulsation during cardiopulmonary resuscitation. JAMA 1992; 267: 379-85.

39. Sack JB, Kesselbrenner MB, Jarrad A. Interposed abdominal compression Cardiopulmonary resuscitation and resuscitation outcome during asystole and electromechanical dissociation. Circulation 1992; 86: 1692-700.

40. Tucker KJ, Galli F, Savitt MA, Kahsai D, Bresnahan L, Redberg RF. Active compression-decompression resuscitation; effect on resuscitation success after in-hospital cardiac arrest. J Am Coll Cardiol 1994; 24: 201-9.

41. Urberg M, Ways C. Survival after cardiopulmonary resuscitation for an inhospital cardiac arrest. J Fam Pract 1987; 25: 41-4. 
42. Ballin NC. A prospective study of 200 cardiopulmonary arrests at the university hospital of the West Indies. West Indian Med J 1986; 35: 88-91.

43. Coskey RL. Cardiopulmonary resuscitation. Impact on hospital mortality: a tenyear study. West J Med 1978; 129: 511-7.

44. Dickey W, Adgey AAJ. Mortality within hospital after resuscitation from ventricular fibrillation outside hospital. Br Heart J 1992; 67: 334-8.

45. George Jr. AL, Folk III BP, Crecelius PL, Campbell WB. Pre-arrest morbidity and other correlates of survival after in-hospital cardiopulmonary arrest. Am J Med 1989; 87: 28-34.

46. Klassen GA, Broadhurst C, Peretz DJ, Johnson AL. Cardiac resuscitation in 126 medical patients using external cardiac massage. Lancet 1963; 1: 1290-2.

47. Linn BS, Yurt RW. Cardiac arrest among geriatric patients. Br Med J 1970; 2: 25-7.

48. Martens PR, Mullie A, Buylaert W, Calle P, Van Hoeyweghen R, The Belgian Cerebral Resuscitation Study Group. Early prediction of non-survival for patients suffering cardiac arrest: a word of caution. Intens Care Med 1992; 18: 11-4.

49. O-Keefe S, Redahan C, KeaneP,Daly K. Age and other determinants of survival after in-hospital cardiopulmonary resuscitation. Quart. J Med 1991; 81: 1005-10.

50. Stephenson Jr. HE. Cardiac resuscitation: what is being accomplished? In Cardiac Arrest \& Resuscitation. $4^{\text {th }}$ ed. Saint Louis: Mosby, 1974: 827-44.

51. Taffet GE, Teasdale TA, Luchi RJ. In-hospital cardiopulmonary resuscitation. JAMA 1988; 260: 2069-72.

52. Carlen PL, Gordon M. Cardiopulmonary resuscitation and neurological complications in the elderly. Lancet 1995; 345: 1253.

53. Gulati RS, Bhan GL, Horan M.A. Cardiopulmonary resuscitation of old people. Lancet $1983 ; 2: 267-9$.

54. Hollingsworth JH. The results of cardiopulmonary resuscitation: a 3-year university hospital experience. Ann Intern Med 1969; 71: 459-66.

55. Kelly CA, Watson DM, Hutchinson CM, Pole JM. Prognostic factors in cardiac arrest occurring in a district general hospital. Br J Clin Pract 1986; 40: 251-3.

56. Lemire SG, Johnson AL. Is cardiac resuscitation worthwhile: a decade of experience. N Engl J Med 1972; 286: 970-2.

57. Linko E, Kaskinen PJ, Siitonen L, Ruosteenoja R. Resuscitation in cardiac arrest. An analysis of 100 successive medical cases. Acta Med. Scand 1967; 182: 611-20.

58. Murphy DJ, Murray AM, Robinson BE, Campion EW. Outcomes of cardiopulmonary resuscitation in the elderly. Ann Intern Med 1989; 11: 199-205.

59. Peatfield RC, Taylor D, Sillet AW, McNicol MW. Survival after cardiac arrest in hospital. Lancet 1977; 1: 1223-5.

60. Scaff B, Munson R, Hartings DF. Cardiopulmonary resuscitation at a community hospital with a family practice residency. J Fam Pract. 1984; 18: 561-5.

61. Stemmler EJ. Cardiac resuscitation: a 1-year study of patients resuscitated within a university hospital. Ann Intern Med 1965; 63: 613-8.

62. Tortolani AJ, Risucci DA, Powell SR, Dixon R. In-hospital cardiopulmonary resuscitation during asystole: therapeutic factors associated with 24 hours survival. Chest 1989; 96: 622-6.

63. Chameides L, Brown GE, Raye JR, Todres DI, Viles PH. Guidelines for defibrillation in infants and children. Report of the American Heart Association target activity group: cardiopulmonary resuscitation in the young. Circulation 1977; 56: 502A-3A

64. Fisher D, Behrman RE. Reanimación del recién nacido. In: Klaus MH, Fanaroff AA. Asistência del Recién Nacido de Alto Riesgo. Buenos Aires: Médica Panamericana, 1978: 17-48.

65. Hock R, Davis CD. Resuscitation of the newborn infant. In: Stephenson Jr. HE. Cardiac Arrest \& Resuscitation. $4^{\text {th }}$ ed. Saint Louis: Mosby, 1974: 453-8.

66. Seidel JS. A needs assessment of advanced life support and emergency medical services in the pediatric patient: state of the art. Circulation 1986; 74(suppl 4): 129-33.

67. Timerman A, Fehér J. Reanimação em recém-nascidos. In: Viegas D, VilhenaMoraes R. Neonatologia Clínica e Cirúrgica (Vol 1). Rio de Janeiro: Atheneu, 1986: 111-26.

68. Zaritsky A. Advanced pediatric life support: state of the art. Circulation 1986; 74(sppl. 4): 124-8

69. Horimoto Y, Yoshizawa M, Okazaki A, Hasumi K. Five years experience of cardiopulmonary resuscitation in a children's hospital. Resuscitation 1985; 13 : $47-55$.
70. O'Keefe S, Ebell MH. Prediction of failure to survive following in-hospital cardiopulmonary resuscitation: comparison of two predictive instruments. Resuscitation 1994; 28: 21-5.

71. Doig CJ, Bostean PJE, Sandham JD. A 2-year prospective cohort study of cardiac resuscitation in a major Canadian hospital. Cl Invest Med 2000; 23: 132-143.

72. Castagna J, Weil MH, Shubin H. Factors determining survival in patients with cardiac arrest. Chest 1974; 65: 527-9.

73. Dupont B, Flensted-Jensen E, Sandoe E. The long-term prognosis for patients resuscitated after cardiac arrest: a follow-up study. Am Heart J 1969; 78: 444-9.

74. Jordan D, Lavin T, Hamelberg W. Resuscitation experience within the hospital. JAMA 1964; 188: 181-2

75. Kaplan BM, Nott Jr. AP. Closed chest cardiac massage for circulatory arrest effectiveness in 100 consecutive cases. Arch Intern Med 1964; 14: 5-12.

76. Levy RD, Rhoden WE, Shearer K, Varley E, Brooks NH. An audit of drug usage for in-hospital cardiopulmonary resuscitation. Eur Heart J 1992; 13: 1665-8.

77. Smith HJ, Anthonisen NR. Results of cardiac resuscitation in 254 patients. Lancet 1965; 1: 1027-9.

78. Goldberg RJ, Gore JM, Haffajee CI, Alpert JS, Dalen JE. Outcome after cardiac arrest during acute myocardial infarcton. Am J Cardiol 1987; 59: 251-5.

79. Johnson AL, Tanser PH, Ulan RA, Wood TE. Results of cardiac resuscitation in 552 patients. Am J Cardiol 1967; 20: 831-5.

80. Kyff J, Puri VK, Raheja R, Ireland T. Cardiopulmonary resuscitation in hospitalized patients: continuing problems of decision-making. Crit Care Med 1987; 15: 41-3.

81. Camarata SJ, Weil MH, Hanashiro PK, Shubin H. Cardiac arrest in the critically ill. I; a study of predisposing causes in 132 patients. Circulation 1971; 44: 68895.

82. Hendrick JMA, Pijls NHJ, Van Der Werf T, Crul JF. Cardiopulmonary resuscitation on the general ward: no category of patients should be excluded in advance. Resuscitation 1990; 20: 163-71.

83. Peterson MW, Geist LJ, Schwartz DA, Konicek S, Moseley PL. Outcome after cardiopulmonary resuscitation in a medical intensive care unit. Chest 1991; 100: 168-74.

84. Kentsch M, Stendel M, Berkel H, Mueller-Esch G. Early prediction of prognosis in out-of-hospital cardiac arrest. Intensive Care Med. 1990; 16: 378-83.

85. Karnofsky DA, Ablemann WH, Craver LF, Burchenal JH. The use of nitrogen mustards in the palliative treatment of cancer. Cancer 1948; 1: 634-41.

86. Brezinski D, Stone PH, Muller JE, et al, The Milis Study Group. Prognostic significance of the Karnofsky performance status score in patients with acute myocardial infarction: comparison with the left ventricular ejection fraction and the exercise treadmill test performance. Am Heart J 1991; 121: 1374-81.

87. Lo B, Davis CD. Resuscitation of the newborn infant. In: Stephenson Jr. HE. Cardiac Arrest \& Resuscitation. $4^{\text {th }}$ ed. Saint Louis: Mosby, 1974: 453-8.

88. Miles SH, Cranford R, Schultz AL. The do-not-resuscitate order in a teaching hospital: considerations and a suggested policy. Ann Intern Med 1982; 96 : $660-4$

89. Stephens RL. "Do not resuscitate" orders: ensuring the patient's participation. JAMA 1986; 255: 240-2

90. Veatch RM. Deciding against resuscitation encouraging signs and potential dangers. JAMA 1985; 253: 77-8.

91. Walker RM. DNR in the OR: Resuscitation as an operative risk. JAMA 1991; 266: 2407-12.

92. Youngner SJ, Lewandowski W, McClish DK, Juknialis BW, Coulton C, Bartlett ET. "Do not resuscitate"orders: Incidence and implications in a medical intensive care unit. JAMA 1986; 253: 54-7.

93. Zimmerman JE, Knaus WA, Sharpe SM, Anderson AS, Draper EA, Wagner DP. The use and implications of do not resuscitate orders in intensive care units. JAMA 1986; 255: 351-6.

94. Girardi LN, Barie PS. Improved survival after intraoperative cardiac arrest in noncardiac surgical patients. Arch Surg 1995; 130: 15-8.

95. Stiell IG, Hebert PC, Weitzman BN, et al. High-dose epinephrine in adult cardiac arrest. N Engl J Med 1992; 327: 1045-50.

96. Hershey CO, Fisher L. Why outcome of cardiopulmonary resuscitation in general wards is poor. Lancet 1982; 1:31-42. 